\title{
PERAN APLIKASI MdB SEBAGAI MEDIA PEMBELAJARAN KEWIRAUSAHAAN BAGI GURU SMK ANGGOTA ASPAPI WILAYAH JAKARTA
}

\author{
${ }^{1)}$ Budi Santoso, ${ }^{2)}$ Marsofiyati, ${ }^{3)}$ Muhammad Yusuf \\ 1,2,3, Dosen S1 Manajemen, S1 Manajemen, Dosen D-III Administrasi Perkantoran \\ Universitas Negeri Jakarta \\ Marsofiyati@unj.ac.id
}

\begin{abstract}
ABSTRAK
Untuk menyiapkan generasi yang berdaya guna serta mampu bersaing di berbagai bidang, peranan orang tua dan guru dalam lingkup memiliki pesanan yang sangat penting, dengan penempatkan pendidikan menjadi suatu prioritas pembangunan negara, maka diharapkan mampu menghasilkan sumber daya manusia yang dapat bersaing. Dengan adanya aplikasi MdB sebagai media pembelajaran kewirausahaan bagi guru SMK di harapkan mampu meningkatkan pembelajaran kewirausahaan.
\end{abstract}

Kata Kunci: Bisnis, Digital, Bisnis Digital

\begin{abstract}
To prepare a generation that is efficient and able to compete in various fields, the role of parents and teachers in the sphere of having a very important order, by placing education as a priority for the country's development, is expected to be able to produce competitive human resources. With the MdB application as a medium of entrepreneurship learning for vocational school teachers, it is hoped that it can improve entrepreneurial learning..
\end{abstract}

Keywords: Business, Digital, Digital Business

\section{PENDAHULUAN}

Tugas pendidikan ialah menyiapkan sumber daya yang berkualitas untuk meneruskan pembangunan. Oleh karena itu pemerintah menempatkan pendidikan sebagai prioritas pembangunan yang berkelanjutan yang mampu menciptakan sumber daya manusia yang unggul pada tataran dunia yang semakin mengglobal. Setiap tingkat dan jenis pendidikan diharapkan mampu mencapai fungsi pendidikan nasional dari berbagai aspek.

Tingkat dan jenis pendidikan yang sekarang menjadi sorotan adalah pendidikan kejuruan atau SMK.

Lulusan SMK wajib memiliki keterampilan yang mumpuni agar dapat bersaing di dunia usaha dan dunia kerja. Salah satu keterampilan yang harus dimiliki siswa SMK adalah keterampilan berwirausaha. Keterampilan berwirausaha adalah sebuah kemampuan yang dimiliki seseorang sebagai bentuk penguasaan Vol. 2, No. 1 | Jurnal Pengabdian Sosial | Tahun 2022 
pengetahuan dan menerapkan pada kegiatan nyata dalam kehidupannya. Penguasaan keterampilan berwirausaha ini sesuai dengan tujuan Sekolah Menengah Kejuruan.

Dalam rangka menghasilkan lulusan yang memiliki jiwa wirausaha yang tinggi, maka perlu dikembangkan model pembelajaran atau pun sebuah program yang dapat menumbuhkan jiwa wirausaha. Ada beberapa program yang dikembangkan di SMK seperti Technopark, Teaching Factory, Koperasi Sekolah, Sekolah Pencetak Wirausaha, dan sebagainya. Salah satu program di SMK yang cukup mendukung adalah Sekolah Pencetak Wirausaha atau yang sering disingkat dengan sebutan SPW. Program ini berguna sebagai wadah serta sarana untuk menumbuhkan jiwa berwirausaha. Dengan adanya program SPW ini di sekolah diharapkan dapat meningkatkan keterampilan siswa dalam berwirausaha.

Pola pikir wirausaha harus dibentuk dengan literasi yang baik dan keberanian melakukan terobosan. Ia menyoroti guru kewirausahaan yang seringkali tidak mengetahui bahwa muridnya sudah berbisnis atau memiliki bisnis. Banyak pula guru kewirausahaan yang senang berada di 'zona nyaman', mengajar dengan referensi yang sudah usang dan tidak mendorong ketertarikan peserta didik.
Guna mendorong guru-guru SMK dalam rangka meningkatkan minat berwirausaha siswa SMK, kami memberikan pelatihan kepada guru-guru SMK, berupa pembelajaran kewirausahaan dengan menggunakan media aplikasi MdB.

MdB adalah aplikasi yang akan menggarap berbagai aspek UKM secara terintegrasi, mulai dari aspek pasar, manajemen, pengadaan bahan baku, akses kredit, akses Crowd funding, akses kerja sama bisnis dan berbagai informasi bagi UKM. Dalam platform MdB akan menggandeng beberapa fihak yang terlibat berkaitan dengan UKM, sebagai mitra antara lain:

- UKM sendiri yang memiliki kebutuhan perluasan pasar, bahan baku, permodalan,dan bimbingan.

- Konsumen, sebagai pembeli produk UKM

- Perbankan, sebagai pemberi pinjaman dan fintech

- Kreditor/ventura langel investor, sebagai calon kemitraan dalam membantu permodalan

- Pabrikan, sebagai supplier bahan baku terhadap kebutuhan UKM

- Logistic, sebagai pendistribusi fisik arus barang

- Kalangan Industri yang menginginkan mitra bisnis UKM 
- Pemerintah, sebagai Pembina UKM berupa pelatihan dan perijinan

- Masih terbuka kemitraan dengan pihak-pihak lainnya

Melalui berbagai interaksi, kemitraan antara tenan diharapkan MdB akan memperoleh berbagai pendapatan berupa fee atau service charge, sebagai streaming incomenya.

\section{TINJAUAN PUSTAKA}

A. Pengertian Bisnis

$\begin{array}{rrr}\text { Bisnis } & \text { adalah } & \text { keseluruhan } \\ \text { rangkaian } & \text { kegiatan } & \text { menjalankan }\end{array}$
investasi terhadap sumber daya yang ada yang dapat dilakukan baik secara individu maupun secara kelompok, untuk memenuhi kebutuhan sehari-hari dan meningkatkan taraf hidup dengan menciptakan barang atau jasa guna mendapatkan laba / keuntungan yang sebesar-besarnya (Hasoloan, 2018).

Kegiatan bisnis dilakukan dalam upaya pemenuhan kebutuhan mulai komersial hingga spiritual kita untuk mencakup kebutuhan hidup seharihari. Dalam setiap detiknya, seluruh orang dunia ini melakukan bisnis, entah itu berbisnis melalui cara jualbeli dan sebagainya.

B. Digital
Digital berasal dari kata Digitus, dalam bahasa Yunani berarti jari jemari. Apabila kita hitung jari jemari orang dewasa, maka berjumlah sepuluh (10). Nilai sepuluh tersebut terdiri dari 2 radix, yaitu 1 dan 0 , oleh karena itu digital merupakan penggambaran dari suatu keadaan bilangan yang terdiri dari angka 0 dan 1 atau off dan on (bilangan biner).

Era digital merupakan suatu masa di mana sebagian besar masyarakat pada era tersebut menggunakan sistem digital dalam kehidupan sehariharinya. Sistem digital mengacu pada bentuk bahasa binari, di mana 'kata' dalam sistem tersebut disebut bits, yang terdiri dari urutan angka 0 dan 1 . Sistem digital ini terbukti lebih mutakhir dari sistem yang dikembangkan sebelumnya, yaitu sistem analog. Kerja sistem analog berbeda dengan sistem digital (Musnaini et al., 2020)

C. Pengertian Bisnis Digital

Menurut Chaffey dalam (Kurniawan \& Wibowo, 2015) Definisi e-Business dapat diartikan sebagai sebuah transformasi informasi yang diaplikasikan secara elektronik dalam sebuah organisasi dan eksternal 
stakeholder untuk mendukung proses bisnis.

Secara umum, E-Business atau Bisnis Online atua Bisnis Digital merupakan sebuah pengaplikasian perkembangan teknologi informasi untuk mempermudah jalanannya proses bisnis hanya melalui laman maya saja, dengan menerapkan sistem e-commerce serta menyediaan kerjasama dalam mendukung jalannya komunikasi dalam sebuah perusahaan. E-Business ini hampir memiliki kesamaan dengan e-commerce dan email mengacu pada penggunaannya yang menggunakan internet untuk memasarkan produk-produknya.

Digital business atau disebut juga bisnis digital adalah bisnis tercanggih saat ini yang diperkirakan terus berkembang setiap tahun dan semakin lama akan meningkat tajam. Bisnis digital di sini adalah bisnis online. Bisnis digital atau bisnis online adalah bisnis riil yang menggunakan media internet. Bisnis digital adalah bisnis yang menggunakan teknologi sebagai keunggulan dalam operasi internal dan eksternal (Musnaini et al., 2020).

Bisnis Digital ialah aktivitas promosi baik itu untuk sebuah brand ataupun produk menggunakan media elektronik (digital). Puluhan tahun silam, media digital marketing sangatlah terbatas, sebutlah televisi atau radio yang hanya dapat menyampaikan informasi secara satu arah.

Jadi dapat disimpulkan bahwa ebusiness adalah sebuah upaya untuk memanfaatkan perkembangan teknologi dalam upaya meningkatkan dan mengubah sistem bisnis utama.

D. Pengertian Aplikasi Distributor

Aplikasi distributor merupakan aplikasi yang dirancang untuk mengelola seluruh aktivitas distribusi pada sebuah bisnis. Aktivitas yang maksud ialah mengelola pesanan, pemantauan harga pasar, pengiriman barang, penagihan dan lain sebagainya. Aplikasi distributor dikenal sebagai DMS (Distrubution Management System). Aplikasi ini memiliki peranan yang penting dalam bisnis digital karena apat meminimalisir kesalahan yang disebabkan oleh kelalaian pegawai. Lalu aplikasi distributor ini dapat mempermudah kegiatan menajemen proses distribusi dalam suatu perusahan.

\section{METODE PELAKSANAAN}

Pelaksanaan pengabdian kepada masyarakat ini dilaksanakan di Jakarta, khususnya di ASPAPI Wilayah DKI Jakarta, dengan peserta guru-guru SMK 
sebagai anggota ASPAPI sebanyak 40 orang guru.

Sekretariat ASPAPI Wilayah DKI Jakarta, pada periode 2019-2023 ini bertempat di Universitas Negeri Jakarta.
Gambar 1. Universitas Negeri Jakarta sebagai Sekretariat ASPAPI Wilayah DKI Jakarta

Sumber: Google Map

Tahapan yang akan dilakukan diantaranya ialah:

a. Mempersiapkan modul pelatihan untuk para guru SMK anggota Aspapi dalam rangka meningkatkan pembelajaran kewirausahaan. b. Melatih guru-guru SMK dalam aspek komunikasi, konten aplikasi dan profiling bisnis dalam rangka meningkatkan pembelajaraan kewirausahaan di SMK.

c. Mengevaluasi peran aplikasi MdB sebagai media Project Based learning Kewirausahaan di SMK.

d. Menyusun laporan kegiatan.

\section{PELAKSANAAN KEGIATAN}

Mitra pada kegiatan pengabdian masyarakat ini adalah guru SMK wilayah DKI Jakarta. Kegiatan Pengmas ini

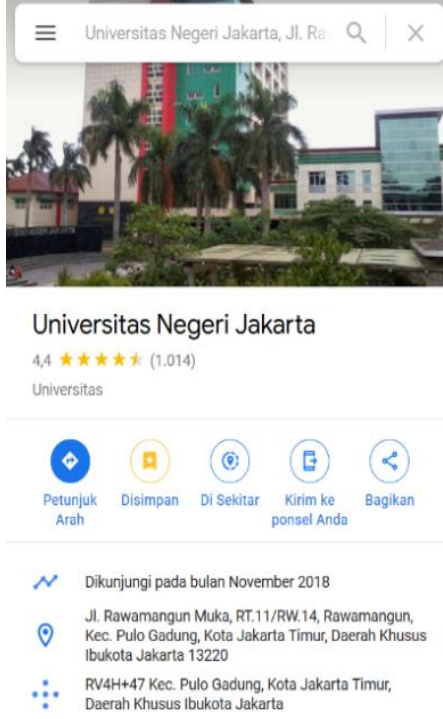

dilaksanakan pada Kamis, 2 September 2021 melalui aplikasi zoom meeting. Kegiatan berjalan dengan baik dan lancar dengan partifipasi aktif dari mitra atau peserta pengmas. 


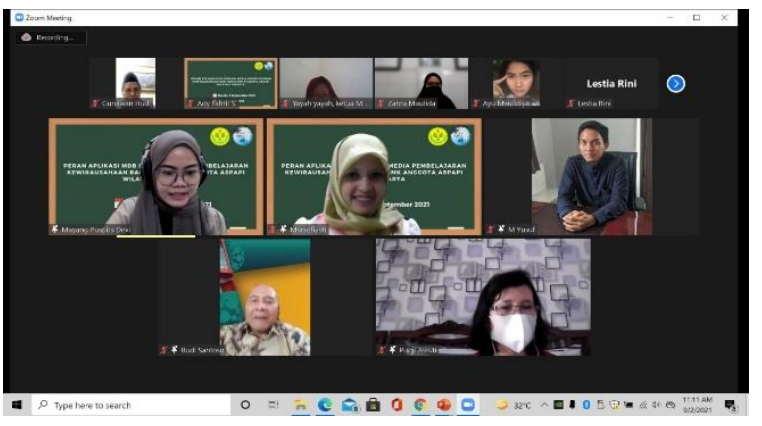

Gambar 2. Pelaksanaan Kegiatan

Melalui kegiatan ini diharapkan dapat membantu dalam mewujudkan program sekolah pencetak wirausaha. Mengingat wirausaha merupakan salah satu sektor yang dapat meningkatkan ekonomi.dalam aplikasi ini pula kami memperkenalkan satu aplikasi yang terintegrasi dengan kemajuan teknologi masa kini.

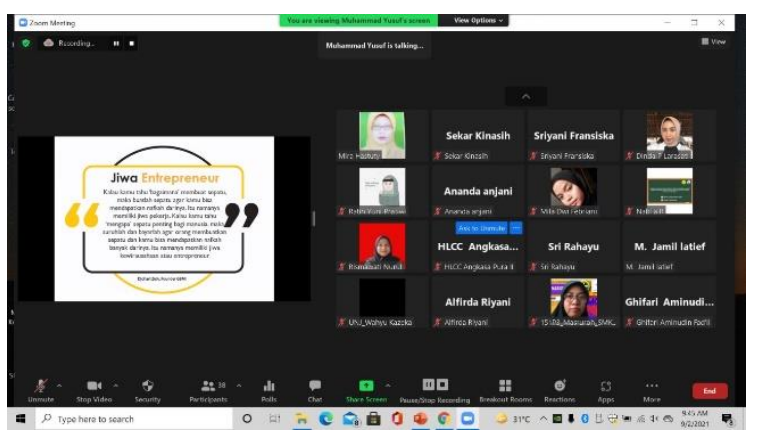

Gambar 3. Pemaparan Materi Pentingnya Berwirausaha oleh M. Yusuf, S.Pd., MM.

Aplikasi yang kami perkenalkan dalam kegiatan pengmas ini adalah aplikasi MdB. Aplikasi ini diciptakan untuk dapat dijadikan satu wadah oleh penggiat UMKM dalam memasarkan barang dagangnya. Dengan kata lain, aplikasi ini merupakan satu bentuk alat pemasaran yang dapat dimanfaatkan UMKM.

Dalam pendidikan, aplikasi MdB ini dapat dijadikan sebagai bahan pembelajaran kewirausahaan. Aplikasi ini dapat menampilkan berbagai UMKM terdaftar serta barang yang dipasarkan sehingga peserta didik mengetahui beberapa jenis UMKM serta barang yang diperdagangkan. Melalui aplikasi ini pula peserta didik dapat melihat mudahnya berwirausaha sehingga dapat meningkatkan minat dalam berwirausaha. Melalui pendidikan tersebut, sangat memungkinkan untuk dapat meningkatkan kemajuan dunia wirausaha dan utama memajukan nilai UMKM dalam membantu perekonomian.

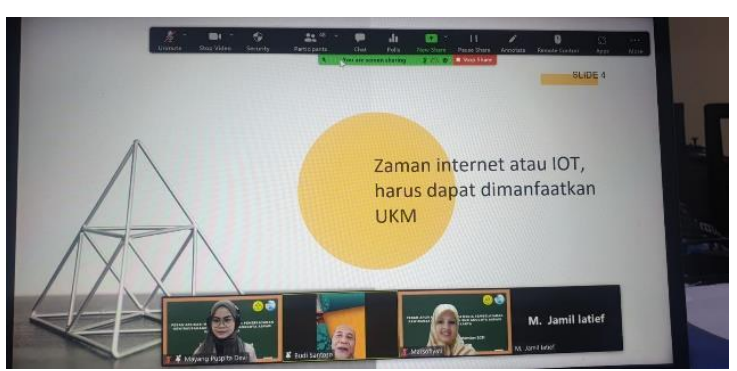

Gambar 4. Pemaparan Materi Peran ICT dalam Kewirausahaan oleh Marsofiyati, S.Pd., M.Pd.

Aplikasi MdB ini memiliki beberapa fitur di dalamnya. Penggunaan setiap fitur akan berbeda sesuai dengan registrasi awal yang dilakukan oleh pengguna. Selaku penggiat atau pemilik UMKM dapat mendaftarkan tokonya pada aplikasi ini dengan melengkapi beberapa data. Data yang dicantumkan merupakan satu bentuk informasi kepada para pengguna lainnya terkhusus bagi para pembeli. Untuk melakukan registrasi sebagai pembeli akan berbeda tahapannya yang tentunya fitur tersebut dibuat dengan sederhana sehinga mudah untuk dipahami. 


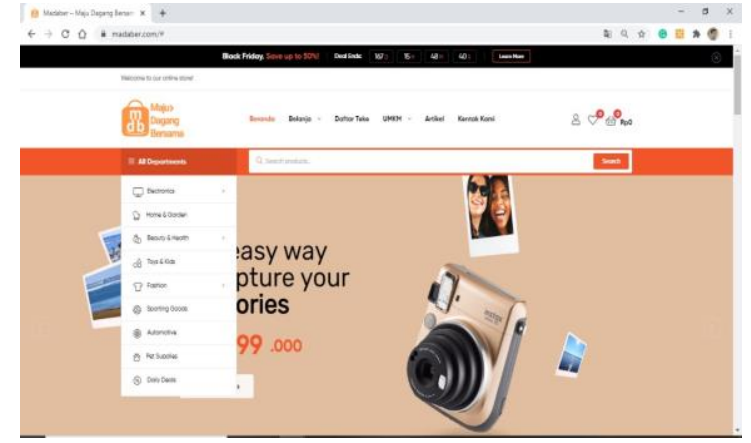

Gambar 5. Interface Aplikasi MdB.

\section{KESIMPULAN}

Pada kegiatan pengabdian masyarakat ini kami memperkenalkan aplikasi MdB kepada para guru untuk dapat dimanfaatkan pada pembelajaran kewirausahaan sebagai media pembelajaran. Adapun instruktur pada pengabdian masyarakat ini adalah DR. Budi Santoso, MM., Marsofiyati, S.Pd., M.Pd., Muhammad Yusuf, MM. dan Ady Fahril S., S.Pd.

Kegiatan dimulai dengan paparan mengenai UMKM dan masalahnya dilanjutkan dengan paparan mengenai aplikasi MdB. Kegiatan berjalan dengan lancar dan menarik. Melalui kegiatan ini akan memberikan gambaran mengenai profil UMKM yang ada dan bentuk pemanfaatan teknologi. Selain itu sebagai bentuk memperkenalkan aplikasi MdB yang kami kembangkan kepada khalayak umum.

\section{DAFTAR PUSTAKA}

Afuah Allan, (2004) Business Models, a strategic Management Approach, , Mc GrawHill , Intl edition.

Campbell , David Campbell; George Stonehouse, Bill Houston, Butterworth Heineman, Business Strategy, $2^{\text {nd }}$ ed 2002 Woburn.

Camisón, C., \& Villar-López, A. (2012). Organizational innovation as an enablerof technological innovation capabilities and firm performance. Journal of Business Research, 67(1), 2891-2902

Charles W.L. Hill, (2008), $5^{\text {th }}$ Ed. Global Business Today, Mc GrawHill, New York USA. Pearson Education 2007. New Jersey.

Craig S Flesher;Babette E. Bensousssan, 2007, Business and Competitive Analysis, Pearson Education. New Jersey.

Hatten, Timothy S,( 2012) Small Business Management Entrepreneurship and Beyond, 5 th ed. Cencage Learning 2012

Nugraha, A. 2018. "Mendikbud Dukung SMK Pencetak Wirausaha”. Sumber dari:

http://jabarekspres.com/2018/mendik bud-dukung-smk-pencetakwirausaha/. diunduh tanggal 22 Januari 2019.

Puryanto. 2018. SMK Pencetak Wirausaha. Diakses dari https://psmk.kemdikbud. go.id/konten/3794/smk-pencetak- 
wirausaha. Diunduh tanggal 11 februari 2019

Republik Indonesia. 2018. Direktur Jenderal Pendidikan Dasar Dan Menengah Kementerian Pendidikan Dan Kebudayaan Tentang Struktur Kurikulum Sekolah Menengah Kejuruan (SMK)/ Madrasah Aliyah Kejuruan (MAK). Lembaran Negara RI tahun 2018, Nomor: 07/D.D5/Kk/2018. Sekretariat Negara. Jakarta.

Rusdiana. 2012. Kewirausahaan Teori dan Praktik. Bandung: CV Pustaka Setia.

Seftiawan, D. 2018. "SMK Didorong Ciptakan Pengusaha Muda". Sumber dari: https://www.pikiranrakyat.com/pendidikan/2018/06/07/s mk-didorong-ciptakan-pengusahamuda-425504. diunduh tanggal 22 Januari 2019.

Tim PPM Manajemen, Business Model Canvas , Penerapan di Indonesia,. Business Model Generation, Alexander Osterwalder. PPM

Wheelen, Thomas L \& Hunger Davis J, “ Strategic Management and Business Policy ", PrenticeHall, 13th edition, 2012.

http://www.depkop.go.id/read/kemkopdan-ukm-targetkan-peningkatankontribusi-umkm-untuk-pdb

Khaidir. 2004. Microsoftjj Visual Basic 6.0. Jakarta : Elex Media Komputindo Hasoloan, A. (2018). PERANAN ETIKA BISNIS DALAM PERUSAHAAN BISNIS. Journal of Physical Therapy Science, 9(57), 1-11.

http://jurnal.dharmawangsa.ac.id/inde x.php/juwarta/article/view/141/136 Kurniawan, A. W., \& Wibowo, A. M. (2015). Makna Bisnis Online Bagi Pengusaha Muda. Jurnal Komunikasi Universitas Garut: Hasil Pemikiran Dan Penelitian, 1(2), 28. https://journal.uniga.ac.id/index.php/J K/article/view/489

Musnaini, M., Jambi, U., Junita, A., Medan, U. H., Wijoyo, H., \& Indrawan, I. (2020). Digital business (1st ed., Issue July). penapersada. 